\title{
A medical student in private practice for a I-month clerkship: a qualitative exploration of the challenges for primary care clinical teachers
}

This article was published in the following Dove Press journal:

Advances in Medical Education and Practice

Virginie Muller-Juge

Anne Catherine Pereira

Miozzari

Arabelle Rieder

Jennifer Hasselgård-Rowe

Johanna Sommer

Marie-Claude Audétat

Unit of Primary Care, Faculty of Medicine, University of Geneva,

Geneva, Switzerland
Correspondence: Marie-Claude Audétat Unit of Primary Care, Faculty of Medicine, University of Geneva, Rue Michel-Servet I, I2II Geneva, Switzerland

Tel +4I 223794389

Fax +4I 223794948

Email Marie-Claude.Audetat@unige.ch
Purpose: The predicted shortage of primary care physicians emphasizes the need to increase the family medicine workforce. Therefore, Swiss universities develop clerkships in primary care physicians' private practices. The objective of this research was to explore the challenges, the stakes, and the difficulties of clinical teachers who supervised final year medical students in their primary care private practice during a 1-month pilot clerkship in Geneva.

Methods: Data were collected via a focus group using a semistructured interview guide. Participants were asked about their role as a supervisor and their difficulties and positive experiences. The text of the focus group was transcribed and analyzed qualitatively, with a deductive and inductive approach.

Results: The results show the nature of pressures felt by clinical teachers. First, participants experienced the difficulty of having dual roles: the more familiar one of clinician, and the new challenging one of teacher. Second, they felt compelled to fill the gap between the academic context and the private practice context. Clinical teachers were surprised by the extent of the adaptive load, cognitive load, and even the emotional load involved when supervising a trainee in their clinical practice. The context of this rotation demonstrated its utility and its relevance, because it allowed the students to improve their knowledge about the outpatient setting and to develop their professional autonomy and their maturity by taking on more clinical responsibilities. Conclusion: These findings show that future training programs will have to address the needs of clinical teachers as well as bridge the gap between students' academic training and the skills needed for outpatient care. Professionalizing the role of clinical teachers should contribute to reaching these goals.

Keywords: clinical teacher, clinical teachers' training, clerkship in private clinical practice, supervision, primary care

\section{Introduction}

Many countries face a lack of primary care physicians to meet the increasing demands in health care because of an aging population suffering from chronic diseases and multimorbidity. ${ }^{1-3}$ Reports have put forward the added value of a strong primary health care system recognizing the role of primary care as a pivotal organization for ensuring proper use of professional skills in the management of such patients. ${ }^{4}$ As Starfield has stated, one of the major challenges to primary care practice concerns recognizing and managing multimorbidity. Outpatient care is therefore at the center of efficient health care system models. ${ }^{5,6}$ In this perspective, it is essential to guarantee the training, from now on, of sufficient primary care physicians in the outpatient context. 
Many studies have highlighted the importance of the learning context for physicians in training, underlining the need for immersion into clinical practice while receiving targeted supervision to develop their competencies. ${ }^{7-9}$ Skills such as history taking, physical examination, patient communication, and professionalism are indeed best learned in the clinical setting. ${ }^{10}$ In this regard, the outpatient setting represents a real challenge, with little time for planned and structured teaching, brief interactions between students and physicians, and little or no control over the organization of working hours, the flow of patients, and the clinical situations. ${ }^{11,12}$ However, it also offers a privileged learning setting that allows the observation and follow-up of acute and chronic illnesses and the teaching of preventive medicine, medical interview communication techniques, as well as psychosocial aspects of various illnesses. ${ }^{12-14}$ Given the reduction in the length of hospital stays, it has also become an excellent setting for students to learn how to manage subacute diseases. ${ }^{11}$ This training could start at a pregraduate level if primary care physicians teach students within their private practices. ${ }^{15}$

Experiences in outpatient setting have been reported as pleasant and fruitful to patients, staff, and students, ${ }^{16}$ but there has been very little research published in the last decade about the experience of primary care supervisors in their private practice.

Seven factors of teaching effectiveness have been described by Irby et al: ${ }^{17}$ knowledge, organization and clarity, enthusiasm, group instructional skills, clinical supervision skills, clinical competence, and modeling professional characteristics. Recent studies on teaching methods tell us that the quality of the supervision depends less on the clinical experience of the physician than on his/her skills as a clinical teacher. ${ }^{7,18,19}$ The latter has to be able to combine two roles: that of a clinician, attentive to the resolution of his/her patient's problem, and that of a teacher, concerned about adapting himself to the needs of his learner and able to support him in his learning. ${ }^{20,21}$

Howe ${ }^{22}$ has stressed the importance of payment and workload as key issues, as well as the need to implement conditions encouraging a "cycle of satisfaction", which increases the likelihood of physicians' long-term commitment to teach. In order for this cycle to work, the clinical teacher should be both motivated and competent. Larsen and Perkins have underlined that the intrinsic motivation is a key factor for primary care physicians to accept teaching, while questions of infrastructure, financial, and other extrinsic rewards seem secondary. ${ }^{23}$
Steinert was interested in the systemic perspective and the challenges related to this pedagogical relationship between supervisor and trainee, especially for students who encounter difficulties. In 2013, she developed a conceptual framework highlighting three different sources for learners encountering difficulties: from the learner himself/herself, from the teacher, and from the context in which they are acting. ${ }^{24}$ She underlined the value of this systemic perspective as a way to develop the reflexive dimension of the teacher when identifying the learner's strengths or weaknesses.

Switzerland, as other countries, faces these challenges. To address this issue, a national program called "the Swiss Masterplan for Primary Care and Family Medicine" ${ }^{25,26}$ was sponsored by the Swiss University Conference and delegated to the five Swiss institutes of primary care medicine.

In this context, a compulsory 1-month clerkship in private practice during the student's final year was recently introduced by Lausanne (2010) and Geneva (August 2015) Medical Schools. In preparation, we developed a 1-month pilot clerkship in Geneva between 2013 and 2015. For this pilot clerkship, clinical teachers who hosted students did not receive any formal pedagogical training but were sent a written guide with basic information and some instructions.

Referring to the conceptual framework proposed by Steinert, as well as to the dual role of the clinical teacher, ${ }^{20}$ the objective of this research was to explore the challenges, the stakes, and the difficulties encountered by clinical teachers who supervised students in their primary care private practice during a pilot rotation for final year medical students in Geneva. The results would provide helpful recommendations that would shape future clerkships and make them sustainable.

\section{Methods}

In this exploratory study, a qualitative approach was used to explore clinical teachers' perceptions and experiences during the rotation. This research was conducted in January 2015 by researchers from the Unit of Primary Care (UIGP), Faculty of Medicine, University of Geneva. Participants provided written consent for participation and for the use of audiorecorded material. The anonymity of the participants, places of work, and cited names were guaranteed.

\section{Setting and participants}

Among 13 primary care physicians working in private clinical practice in Geneva who had hosted a final year medical student for a 1-month pilot clerkship between 2013 and 2015, 10 were invited by e-mail to participate in the study and be part of a 
focus group meeting. Three were excluded for various reasons: two of them were part of our UIGP and had a close contact with our researchers' team and one of them was excluded for various reasons. The selection process was on a voluntary basis, and five of the clinical teachers agreed to participate (Table 1).

\section{Data collection}

All data were collected during a single focus group. The focus group method was selected in order to garner the depth and complexity of responses and to gain the benefits of group interaction. ${ }^{27}$ The focus group took place in a room of the Medical School of the University of Geneva. Two researchers (a physician and a medical education specialist) conducted the focus group, and one researcher (an educational scientist) observed and took some notes.

First, the participants were asked to describe themselves and provide sociodemographic characteristics (years of experience in private practice, type of private clinical practice [small or big structure and number of physician(s) working in the private practice], specificity of the clinical practice [eg, specialization in homeopathy], and date of clerkship) (Table 1).

Then, the interviewers conducted the focus group, asking the participants about their role of supervisor, the difficulties and satisfactions they had experienced, and their needs for the future as clinical teachers.

The interview guide (Supplementary material) was pretested 1 month before the focus group with two clinical teachers who did not participate in the study. The focus group was audio recorded, transcribed, and anonymized. The focus group interview was conducted in French and the transcription was translated to English by Jennifer Hasselgård-Rowe.

\section{Analysis}

Content analysis was used to analyze the data, using a deductive and inductive approach. ${ }^{28}$ It was deductive because the code categories relating to the conceptual framework of Steinert $^{24}$ were first used and inductive because new content was then coded and classified according to the method described by Saldana. ${ }^{29}$ The quality of the analysis was reinforced by the triangulation of the researchers.

First, two researchers consisting of a family physician (ACPM) and an educationalist (VM-J) independently identified, coded, and classified the content of the transcripts using the ATLAS.ti software (version 7.5.3; ATLAS.ti Scientific Software Development GmbH, Berlin, Germany). They then compared and discussed their coding until a consensus was reached. The third researcher (M-CA) cross-checked the coding.

\section{Ethics approval and informed consent}

The study was granted a waiver from approval by the Research Ethics Committee of Geneva, because it did not include any patients for the data collection. Participants provided written consent for participation and for the use of audio-recorded material.

\section{Results}

The results were divided into the following three categories: the clerkship context, the students and the optional clerkship, and the clinical teachers and the student-teacher relationship. These categories correspond to the three poles suggested in Steinert's conceptual framework.

\section{The clerkship context}

All the participants mentioned the relevance of the clerkship for the students, as it enabled them to discover the specificities of outpatient care. Indeed, these students had the opportunity to immerse themselves into the reality of outpatient settings and, for the first time, were able to take care of patients as a whole and as a part of an ongoing process.

Table I Participants' characteristics

\begin{tabular}{|c|c|c|c|c|c|}
\hline $\begin{array}{l}\text { Clinical } \\
\text { teachers }\end{array}$ & Gender & $\begin{array}{l}\text { Number of years } \\
\text { of experience in } \\
\text { private practice }\end{array}$ & $\begin{array}{l}\text { Type of private } \\
\text { clinical practice }\end{array}$ & $\begin{array}{l}\text { Specificity of the clinical } \\
\text { practice }\end{array}$ & $\begin{array}{l}\text { Date of the clerkship and number of } \\
\text { received student(s) }\end{array}$ \\
\hline $\begin{array}{l}\text { Clinical } \\
\text { teacher I }\end{array}$ & $M$ & $\mathrm{I}$ & Large structure & Not specified & $\begin{array}{l}\text { Two students in May } 2014 \text { and in October } \\
2014 \text {, in tandem with a colleague }\end{array}$ \\
\hline $\begin{array}{l}\text { Clinical } \\
\text { teacher } 2\end{array}$ & $M$ & 3 & Large structure & Not specified & $\begin{array}{l}\text { Two students in Mai } 2014 \text { and in October } \\
2014 \text {, in tandem with a colleague }\end{array}$ \\
\hline $\begin{array}{l}\text { Clinical } \\
\text { teacher } 3\end{array}$ & $M$ & 20 & $\begin{array}{l}\text { Group practice of } \\
\text { four physicians }\end{array}$ & $\begin{array}{l}\text { Specialization in endocrinology } \\
\text { and diabetology }\end{array}$ & $\begin{array}{l}\text { One student in November } 2014 \text {, in } \\
\text { tandem with a colleague }\end{array}$ \\
\hline $\begin{array}{l}\text { Clinical } \\
\text { teacher } 4\end{array}$ & $\mathrm{~F}$ & 24 & $\begin{array}{l}\text { Group practice of } \\
\text { two physicians }\end{array}$ & $\begin{array}{l}\text { Specialization in homeopathy and } \\
\text { burnout }\end{array}$ & One student in November 2014 \\
\hline $\begin{array}{l}\text { Clinical } \\
\text { teacher } 5\end{array}$ & $\mathrm{~F}$ & 31 & $\begin{array}{l}\text { Group practice of } \\
\text { two physicians }\end{array}$ & $\begin{array}{l}\text { Specialization in psychosomatic } \\
\text { illnesses }\end{array}$ & One student in August 2014 \\
\hline
\end{tabular}

Abbreviations: F, female; $M$, male. 
They are not at all the same patients as in the hospital context. [...] [At the hospital], in a sense, the triage has already been done. [...] For us, the difficulty is to catch the ones who are headed in a bad direction. [Clinical teacher 2]

This clerkship also enabled students to go beyond their initial prejudices regarding primary care.

She [the student] came to this clerkship to confirm that indeed primary care medicine was not what she needed but she left saying: "Is it possible to come back as a resident here, it interests me and, well, I can imagine myself in this, this specialty". [Clinical teacher 1]

As a matter of fact, it is, it was also very surprising how she came not only with her own personal baggage but also with prejudices such as: Outpatient care, internal medicine, private practice, it's a bit. [Clinical teacher 2]

[...] Sore throats and [brand name of Bromazepam]. [Clinical teacher 1]

[...] Because we do geriatrics. [Clinical teacher 4]

The clinical teachers discovered that in what ways this clerkship context could help the students to develop autonomy and professional maturity.

What surprised me, is how cool she found this clerkship. [...] To have a desk. [...] To have patients. [...] To be able to discuss things with them, examine them. She was very surprised. And I wasn't necessarily expecting that. [Clinical teacher 2]

By talking with the student, she [the student] said that she did a lot of clerkships as an observer, where finally she follows the resident. [Clinical teacher 2]

All the participants also noted the positive way that patients not only accepted the students but also valued their physicians' role of supervisor in the context of their private practice. However, it must be noted that all the patients got the chance to see their physician at a certain point during their consultation.

I would like to go back to the point of explaining the clinical reasoning. On the one hand I found it to be a very interesting exercise for me and it had completely surprising effects on the patients who, frequently, were extraordinarily happy to hear all that I was doing. [Clinical teacher 5]

In the end, I think that the patients found the idea that we were trainers rather nice. I have the impression that for them, it was more important to realise that we had the capacity to train, rather than saying to themselves: "Ah, I am going to be taken care of by a learner". [Clinical teacher 1]

\section{The students and the optional clerkship}

For this pilot clerkship, the students were volunteers and most of them were interested in specializing in primary care medicine.

And, in fact, what remains a worry for me is that I am conscious of the fact that we didn't have so-called normal students, we had very willing, very motivated people who did an optional clerkship. And that, that's ok, we won't have this population sample from this year onwards. There we go, so it is true that what worries me is more how we will manage difficult students. [Clinical teacher 1]

\section{The clinical teachers and the student- teacher relationship}

All the clinical teachers of this study expressed a feeling of gratification linked to supervising a student in their private practice. They clearly considered themselves as a role model and initiator, enthusiastically describing the teaching moments when the student was able to discover a new aspect of his/her future job or to practice a medical intervention "for the first time".

So, I was able to supervise her for her first stitches. [...] There were the stitches, so I had to redo a few but I mean I showed her and afterwards she was able to do them. [...] And I found that this was a good moment because it's like getting someone to stand on his own feet. [Clinical teacher 5]

One of the magical moments was when we had the "luck" to have a case of pneumonia with a pleural rub. [...] And when she heard that, I really got the impression that she saw the light. Because she said: "I have heard so much about this pleural rub, I couldn't imagine what it was and there, we heard it so well". [...] And that I found really neat because she was surprised herself by what one can discover. [Clinical teacher 4]

Nevertheless, the clinical teachers also highlighted the lack of clearly defined learning objectives and assistance with regard to the organization of the student's venue into the private practice. They also noted the students' lack of specific knowledge in outpatient medicine, which made their supervisory task more difficult.

So I think that for me it was difficult to define learning objectives, because the hospital model gives students objectives for everything, they don't formulate them themselves. So there were difficulties in being curious enough to say: "Well hang on, I would need this". [Clinical teacher 5] 
There would certainly be important preparatory work to be done, which could easily be done beforehand, outside the private practice, which would make my task easier. [Clinical teacher 5]

So, they used their personal resources and motivations to define the objectives.

I had to make up the instructions. [...] The first day, you interview some patients, she is sitting next to you; the second day, she interviews some patients and you are sitting next to her and the third day she starts interviewing some patient by herself. [...] Did I invent the instructions or what? [Clinical teacher 4]

I am the one who developed this objective for myself because I found that as a teacher, I cannot say to her: "Now you give him the [brand name of: Enalapril] and it's done". [Clinical teacher 4]

They used these same individual competencies and qualities, with creativity and proactivity, to integrate the student in the private practice.

In our case, one month before the clerkship we prepared a nice little flyer with a little drawing. We explained them [the patients] that we are a private practice that trains students; that in a month they might have a student [as doctor], that they were free to say yes or no. [Clinical teacher 4]

All the participants said that they were "pushed around" by the arrival of a student in their context: first, they had to resolve logistical problems such as the lack of devoted space and the reorganization of the consultation plan. The structure of group practices with several physicians clearly facilitated the organization of the work and the joint management of patients.

We did what we could to accommodate the student as much as possible. [...] It is very difficult to host someone [a student] into a practice with two doctors or in a place where there are 10 primary care physicians in addition to the specialists, an entire administrative staff, the assistants and the X-ray centre. [...] It requires preparation. [Clinical teacher 1]

From an organizational point of view, I think that little by little, it will be necessary to create a manual "clinical teachers for dummies". [Clinical teacher 3]

For me, it's one of the reasons for which I will no longer take in a 6 th year medical student. Because for me, it seems extremely difficult as long as we haven't solved the room problem. [Clinical teacher 3]
The clinical teachers felt disorganized in their usual work rhythm by the arrival of a third person in their work environment.

I was much more tired in the evenings. Normally I go home [...], I am not tired. But here, I went home, I was tired because there were always unexpected things and I still had to watch her for hours because she had a tendency to go over time. [Clinical teacher 4]

I hope that the students will be sensitive to that, prepared for that, to not be disruptive, because it's still an adaptation for us to host a student. [Clinical teacher 1]

I have a huge office for me so I left her my desk. [...] But I wouldn't do it for two months in a row. [...] I was exhausted at the end. [Clinical teacher 4]

Explaining their clinical reasoning and practices to the student was an effort for all of the clinical teachers. This represented an unexpected cognitive load, which led to tiredness and loss of efficacy.

It's an effort to explain common things clearly. It's true that one has to make an effort to put words on things that are obvious for us. [Clinical teacher 3]

I found it difficult to conceptualise the automatic reflexes that we have. [...] And that was really difficult for me: to put words on, to formulate why I chose this and then not that, and then why I put this [treatment] but not that. [Clinical teacher 4]

In addition, the clinical teachers described some unease and uncertainty in the patient-student-teacher triad.

My student was leading the interview [with the patient] and then [...] I was able to assist a bit from the outside and thought " hmm... it works between the two of them". One could feel that they had good chemistry between them. The patient was not looking at me but at her, $[\ldots]$ I found that it was a rather strange moment, to be in my own practice and to see that someone else suddenly arrives and creates this kind of bond. I could just get up and leave. [Clinical teacher 2]

I am rather protective of my patients. Obviously, I know them since a long time. I realised I was afraid that my patients would be pushed around, I wouldn't say mistreated because I didn't think she was really going to mistreat them. [...] But still, I was worried that things would go well, that there would not be any clashes. I also have relatively fragile patients in my specialty. Actually, I still needed to have control over what was happening. [Clinical teacher 5] 
Finally, when the clinical teachers reported their supervisions, they primarily described an interactive model, essentially centered on the clinical case management. They described themselves as role models, concerned about transmitting their interest for primary care, and using specific teaching methods addressing the needs of their student.

For us, our job description was: "This clerkship has been created because there are not enough primary care physicians and people have to like primary care and realise that it is not boring". [Clinical teacher 1]

I am relatively convinced that everyone has not learned how to supervise, full stop. I still think that we come from a profession where I think that we have all been trained [...] to: "See one, do one, teach one" [...] That's it. And, um, I think that today it's something else. [Clinical teacher 2]

\section{Discussion}

The objective of this research was to explore the challenges, the stakes, and the difficulties of clinical teachers who supervised final year medical students in their primary care private practices during a 1-month pilot clerkship in Geneva.

The clerkship context demonstrated its utility and its relevance, as supervisors felt that it enabled students to better discover the outpatient context and to develop their professional autonomy and maturity by taking on more clinical responsibilities. The month spent within the medical private practices also enabled some students to go beyond their prejudices and to better understand the challenges and reality of outpatient medicine as well as the specific work of primary care physicians in private practices. On the patients' side, they accepted the students and appreciated their physician also being a teacher, as described by Latta. ${ }^{30}$

However, this clerkship context also revealed weaknesses: the clinical teachers found that the students' curriculum was not sufficiently related to the reality of primary care. Indeed, it was difficult both for the students, unfamiliar with the context, and the clinical teachers, not knowing what they could expect from their students, to define specific learning objectives. Finally, the contexts as well as the clinical teachers' teaching skills were very heterogeneous and it made these clerkships very enriching but potentially, also very unequal.

The clinical teachers reported enthusiastic and motivated students. This had very positive consequences on their own motivation and enhanced their investment in their teaching role. These findings are consistent with the cycle of satisfaction described by Howe. ${ }^{22}$ However, we must take into account that the students were all volunteers for this pilot clerkship and mostly committed to a primary care career. This highlights the potential challenge of supervising less motivated students and/or with difficulties, such as communication, professionalism, and clinical reasoning difficulties. It also shows the potentially negative impact that these difficulties could have on clinical teachers' motivation to host students in the future.

Nevertheless, the clinical teachers reported feeling highly valued and motivated by the opportunity to promote the job of primary care and to "witness" key moments in their student's professional development.

As described by Larsen and Perkins, ${ }^{23}$ the principal factor for clinical teachers to host students in their practice consists of their motivation and intrinsic satisfaction to transmit their enthusiasm and passion for primary care medicine. Thus, they supervised their students using their sense of organization, enthusiasm, intuition, and personal experience of supervision, more than relying on defined teaching skills, but they felt uncomfortable, when unexpected situations concerning student occurred.

Clinical teachers faced different loads: first, an organizational load, which is also identified in other studies, ${ }^{22,31}$ due to the reorganization of their consultation plan, their offices, and their rhythm of work. Second, a cognitive load was less expected by the clinical teachers: they realized how tiring it is, cognitively speaking, to share the different steps of their clinical reasoning with their students..$^{32}$ Indeed, as the clinical teachers are experts, their reasoning is encapsulated in their memory. ${ }^{33,34}$ Finally, the clinical teachers reported their students as somehow invading their personal symbolic territory (their desk and their space) and their caring relationship (with their patients). This represents a third load on an emotional level, which was disruptive and not at all expected by the participants.

From our perspective, these different factors explain why the success of this clerkship is very fragile in the mid or long term (Figure 1). These results reveal a risk of exhaustion and/or frustration of the clinical teachers who, as it is already the case for some of the focus group members, may consider not renewing the experience. This clearly illustrates one of the challenges linked to the sustainability of the clerkship.

To strengthen the clinical teachers' role, a formal curriculum development program should be defined as already highlighted by Larsen and Perkins. ${ }^{23}$ Irby $^{12}$ has stressed the need for faculty development programs in order to help 


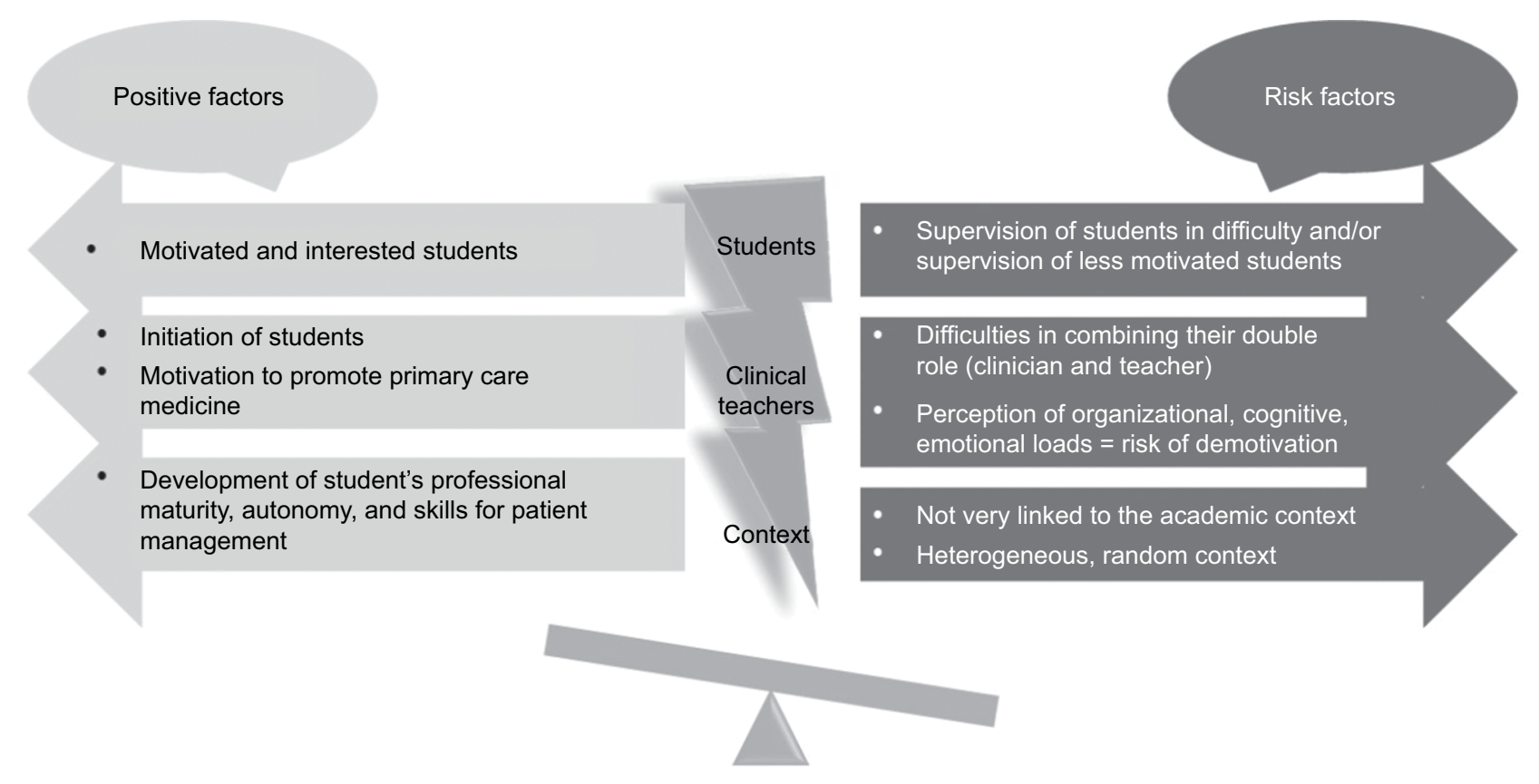

Figure I Balance between positive factors and risk factors for the success and sustainability of the clerkship.

clinical teachers to teach within the existing time constraints as well as to tailor their teaching to the learner's needs.

Accordingly, it is important to professionalize the clinical teachers' role by developing their professional identity as a teacher. ${ }^{19,35}$ This would reinforce their position as a supervisor, by enriching their teaching skills and by making them more efficient. This would make the clinical teachers feel more comfortable in their role as supervisor and help them better manage their supervisory time as well as the cognitive and emotional loads mentioned earlier.

From this perspective, a longitudinal faculty development curriculum should be devised in order to support the clinical teachers in the long term. A follow-up by individualized coaching could also contribute to the sustainability of the teaching skills and encourage the clinical teachers to host new students.

Finally, we have to mention that clinical teachers may have to manage students in difficulty: research results have shown that without targeted remediation, struggling learners simply spend more time using previously unsuccessful strategies rather than changing them and, therefore, are more likely to fail again; ${ }^{36,37}$ that is why remediation strategies should follow the basic tenets of early identification and diagnosis of specific areas of deficiency. They should be based on learners' greatest deficits and incorporate deliberate practice, feedback, and reflection. Clinical teachers need to be trained to be able to reach these goals. ${ }^{38-40}$

These results lead us to define the following suggestions:
- The institution responsible for the clerkship needs to closely support the clinical teachers by giving them very practical instructions for accommodating a student, organizing the consultation plan, and for reducing the organizational complexity of the clerkship.

- The clerkship must be integrated in the student's curriculum, particularly by clearly transmitting the learning objectives to the students and the clinical teachers.

- The primary care physicians' role as a trainer must be recognized and explicitly valued within their private practice, for example, by giving an official certificate to the clinical teachers or by providing the patients with documents about the teaching role of their physician. This is a motivating factor and strengthens this role from the patients' perspective.

- Faculty development needs to ensure that clinical teachers master teaching skills in order to deliver major elements of the curriculum, to define a student-centered learning objective while respecting the time constraints of clinical practice. A longitudinal faculty development program including possible personalized coaching will support long-term sustainability.

- Clinical teachers can supervise a student in teaching pairs, either in a group practice or in a medical center; thus, the responsibilities and tasks can be shared, and this lightens the teachers' role. A joint pedagogical follow-up can be organized by sharing their perceptions, successes, and difficulties. 


\section{Strengths and limitations}

These results allow us to identify some key challenges. It is a first step in understanding the unexpected loads and the risk factors that could lead supervisors to gradually withdraw from the internship. The low number of participants in the focus group, due to the fact that only 13 physicians hosted students for this pilot clerkship, represents a limitation for this study. However, the participants were representative of our clinical teacher population, insofar as their age and years of experience of clinical practice differed. A homogenous distribution between men and women and between small, medium-sized, and big practices was also present. It, therefore, constituted a varied and representative sample of primary care physicians in Geneva and allowed to reach data saturation.

There is no doubt that the perspective of both students and teachers would be a real benefit in this kind of study. Nevertheless, in the specific context of this pilot clerkship, the students concerned were not representative of the whole student population. Indeed, they were all interested by primary care specialization and they had consequently chosen to participate to this pilot experience. Further studies should explore the students' perceptions and also teachers' perception with less motivated students.

\section{Conclusion}

This research enabled us to highlight that the clinical teachers' perceived relevance of this clerkship. These results also allowed us to identify the factors positively reinforcing the clinical teachers' role as well as those likely to question its success and its sustainability. Given the large number of clinical teachers needed, it is important to assist them in their administrative and organizational work, as well as in their dual role of clinician and supervisor by training them in a formal and targeted faculty development program. This will contribute to the retention of clinical teachers as well as the sustainability of the clerkship.

A new study is currently being conducted and aims to better identify the teaching methods used by the clinical teachers and their pedagogical needs in order to develop future training activities. The results will bring new and complementary elements to this first study by also aiming to improve the effectiveness of supervision in private clinical practices.

\section{Data availability}

The dataset analyzed during the current study is available from the corresponding author on reasonable request.

\section{Acknowledgments}

We thank the clinical teachers who participated in the study. We also thank Cédric Gillabert for his contribution to study design and recruitment of participants. We are grateful to Lionel Voirol for transcribing the audiotaped focus group.

This study received a grant from CUS SUK-Programm P-10 "Konsolidierung von Lehre und Forschung im Bereich Hausarztmedizin/medizinische Grundversorgung" in the context of the master plan for primary care.

\section{Author contributions}

MCA, ACPM, VMJ, AR, and JS designed the study. MCA, ACPM, and VMJ conducted the focus group. All authors contributed toward data analysis, drafting and critically revising the paper, gave final approval of the version to be published, and agree to be accountable for all aspects of the work.

\section{Disclosure}

The authors report no conflicts of interest in this work.

\section{References}

1. Salisbury C. Multimorbidity: redesigning health care for people who use it. Lancet. 2012;380:7-9.

2. Peytremann-Bridevaux I, Ebert ST, Senn N. Involvement of family physicians in structured programs for chronic diseases or multi-morbidity in Switzerland. Eur J Intern Med. 2015;26(2):150-151.

3. Mathers C, Loncar D. Projections of global mortality and burden of disease from 2002 to 2030. PLoS Med. 2006;3(11):e442.

4. Fortin M, Chouinard M, Bouhali T, Dubois M, Gagnon C, Belanger M. Evaluating the integration of chronic disease prevention and management services into primary health care. BMC Health Serv Res. 2013;13:132.

5. Starfield B. New paradigms for quality in primary care. Br J Gen Pract. 2001;51:303-309

6. Starfield B, Shi L, Macinko J. Contribution of primary care to health systems and health. Milbank Q. 2005;83(3):457-502.

7. Chamberland M, Hivon R. Les compétences de l'enseignant clinicien et le modèle de rôle en formation clinique [Needed competences for clinical teachers and role model in the clinical setting]. Pédagogie Médicale. 2005;6:98-111. French.

8. Kolb D. Experiential Learning: Experience as the Source of Learning and Development. Englewood Cliffs, NJ: Prentice-Hall; 1984.

9. Yardley S, Teunissen P, Dornan T. Experiential learning: AMEE Guide No. 63. Med Teach. 2012;34(2):e10215.

10. Spencer J. Learning and teaching in the clinical environment. ABC of learning and teaching in medicine. Br Med J. 2003;326:591-594.

11. Ramani S, Leinster S. Teaching in the clinical environment: AMEE Guide No 34. Med Teach. 2008;30:347-364.

12. Irby D. Teaching and learning in ambulatory care settings: a thematic review of the literature. Acad Med. 1995;70(10):898-931.

13. McGee S, Irby D. Teaching in the outpatient clinic. Practical tips. $J$ General Int Med. 1997;12(suppl 2):S34-S40.

14. Dent JA. AMEE Guide No 26: clinical teaching in ambulatory care settings: making the most of learning opportunities with outpatients. Med Teach. 2005;27(4):302-315.

15. Worley P, Esterman A, Prideaux D. Cohort study of examination performance of undergraduate medical students learning in community settings. BMJ. 2004;328(7433):207-209. 
16. Dent JA, Angell-Preece HM, Ball HM-L, Ker JS. Using the ambulatory care teaching centre to develop opportunities for integrated learning. Med Teach. 2001;23(2):171-175.

17. Irby D, Ramsey P, Gillmore G, Schaad D. Characteristics of effective clinical teachers of ambulatory care medicine. Acad Med. 1991;66(1):54-59.

18. Srinivasan M, Le S, Meyers FJ, et al. "Teaching as a competency": competencies for medical educators academic medicine. Acad Med. 2011;86(10):1211-1220.

19. Hesketh E, Bagnall G, Buckley E, et al. A framework for developing excellence as a clinical educator. Med Educ. 2001;35(6):555-564.

20. Audétat MC, Laurin S. Clinicien et superviseur, même combat! [Clinician and supervisor, same battle!] Le Médecin du Québec. 2010;45(5):53-57. French.

21. Audétat MC, Laurin S, Sanche G. Aborder le raisonnement clinique du point de vue pédagogique. I. Un cadre conceptuel pour identifier les problèmes de raisonnement clinique chez les étudiants [Tackling clinical reasoning from a pedagogical perspective. A conceptual framework to identify clinical reasoning difficulties]. Pédagogie Médicale. 2011;12(4):223-229. French.

22. Howe A. Teaching in practice: a qualitative factor analysis of community-based teaching. Med Educ. 2000;34(9):762-768.

23. Larsen K, Perkins D. Training doctors in general practices: a review of the literature. Aust J Rural Health. 2006;14(5):173-177.

24. Steinert Y. The "problem" learner: whose problem is it? AMEE Guide No. 76. Med Teach. 2013;35:e1035-e1045.

25. Tandjung R, Ritter C, Haller D, et al. Primary care at Swiss universities - current state and perspective. BMC Res Notes. 2014;7(308):2-8.

26. Office fédéral de la santé publique (OFSP). Masterplan "médecine de famille et médecine de base" [Masterplan "family medicine and basic medicine]. 2012. Available from: https:/www.bag.admin.ch/bag/fr/ home/themen/berufe-im-gesundheitswesen/medizinalberufe/medizinische-grundversorgung/masterplan-hausarzt-med-grundversorgung html. Accessed November 25, 2017. French.

27. Krueger R, Casey M. Focus Groups. 3rd ed. Thousand Oaks, CA: Sage; 2000.

28. L'Ecuyer R. L'analyse de contenu: notions et étapes. In: Deslauriers $\mathrm{J}$, editor. Les méthodes de la recherche qualitative. Sillery: Presses Universitaires du Québec; 1988:49-65.
29. Saldana J. The Coding Manual for Qualitative Researchers. Los Angeles, CA: Sage Publication; 2011.

30. Latta L, Tordoff D, Manning PJ, Dent JA. Enhancing clinical skill development through an Ambulatory Medicine Teaching Programme: an evaluation study. Med Teach. 2013;35(8):648-654.

31. Dent JA, Ker JS, Angell-Preece HM, Preece PE. Twelve tips for setting up an ambulatory care (outpatient) teaching centre. Med Teach. 2001;23(4):345-350.

32. van Merriënboer JJG, Sweller J. Cognitive load theory in health professional education: design principles and strategies. Med Educ. 2010;44(1):85-93.

33. Bordage G, Lemieux M. Semantic structures and diagnostic thinking of experts and novices. Acad Med. 1991;66(9):S70-S72.

34. Schmidt H, Rikers R. How expertise develops in medicine: knowledge encapsulation and illness script formation. Med Educ. 2007;41(12):1133-1139.

35. Audétat MC, Dory V, Nendaz M, et al. What is so difficult about managing clinical reasoning difficulties? Med Educ. 2012;46(2):216-227.

36. Guerrasio J, Garrity M, Aagaard E. Learner deficits and academic outcomes of medical students, residents, fellows, and attending physicians referred to a remediation program, 2006-2012. Acad Med. 2014;89(2):352-358.

37. Cleland J, Leggett H, Sandars J, Costa MJ, Patel R, Moffat M. The remediation challenge: theoretical and methodological insights from a systematic review. Med Educ. 2013;47(3):242-251.

38. Audétat M-C, Laurin S, Dory V, Charlin B, Nendaz M. Diagnosis and management of clinical reasoning difficulties: part I. Clinical reasoning supervision and educational diagnosis. Med Teach. 2017;39(8): 792-796.

39. Audétat M-C, Laurin S, Dory V, Charlin B, Nendaz M. Diagnosis and management of clinical reasoning difficulties: part II. Clinical reasoning difficulties: management and remediation strategies. Med Teach. 2017;39(8):797-801.

40. Boileau E, St-Onge C, Audétat M. Is there a way for clinical teachers to assist struggling learners? A synthetic review of the literature. Adv Med Educ Pract. 2017;8:89-97. 


\section{Supplementary material}

\section{Interview guide of the focus group}

1. Recall a specific supervisory moment with your student (focus on the student) during the clerkship that was particularly satisfying and tell us why.

- What surprised you in a good or bad way during the clerkship?

- What are the main strengths that you identified in your students?

2. What were the main difficulties that you encountered with regard to your student?

(sub-questions referring to the conceptual framework)

3. How did you feel?

- What did you do about those feelings?

- What strategy(ies) did you use to deal with the difficulty you encountered with regard to your student?
4. How would you describe the main difficulties that you encountered as a tutor?

- During the various teaching moments? (referring to different moments such as when discussing particular cases, when the patient was present, when observing the student, in relation to the structure of the private practice, or regarding the processes in place for making the supervision easier).

5. How did you react?

- What strategy(ies) did you use with this teaching difficulty?

6. What would you say the training tools and needs for future clerkships are?

7. Would you reiterate/repeat your experience as a tutor in the future?

Comment: questions 1-3 focus on the student, and questions 4-7 focus on the clinical teacher.

\section{Publish your work in this journal}

Advances in Medical Education and Practice is an international, peerreviewed, open access journal that aims to present and publish research on Medical Education covering medical, dental, nursing and allied health care professional education. The journal covers undergraduate education, postgraduate training and continuing medical education including emerging trends and innovative models linking education, research, and health care services. The manuscript management system is completely online and includes a very quick and fair peer-review system. Visit http://www.dovepress.com/testimonials.php to read real quotes from published authors. 